\title{
ROLE Of RADIOFREQUENCY DENERVATION IN LUMBAR ZYGAPOPHYSEAL Joint Synovitis in Baseball Pitchers: A Clinical Experience
}

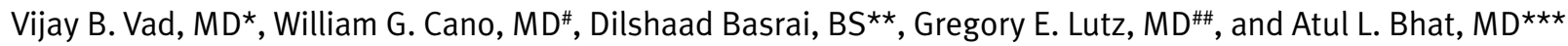

\begin{abstract}
Lumbar zygapophyseal joints have long been considered a source of low back pain with or without leg pain. The objective of this prospective study was to investigate the therapeutic effectiveness of lumbar zygapophyseal joint radiofrequency denervation (RFD) followed by physical therapy, for the treatment of refractory lumbar zygapophyseal joint mediated low back pain secondary to lumbar zygapophyseal joint synovitis, in baseball pitchers.

Participants included twelve male baseball pitchers with a diagnosis of lumbar zygapophyseal joint synovitis mediated low back pain and a subsequent difficulty in pitching. These athletes underwent a trial of treatment, including oral anti-inflammatory medication, physical therapy, osteopathic manipulations, and fluoroscopically guided
\end{abstract}

Low back pain is the second most common reason for a visit to the primary care physician (1). Various spinal structures that are innervated by pain generating nociceptive fibers, which could be implicated, include the intervertebral disc, ligaments, facet or zygapophyseal joints, sacroiliac joints, vertebral periosteum and bone, blood vessels, and spinal nerve roots (2). Lumbar zygapophyseal joint or facet joint is reported to have a prevalence of $15 \%-52 \%$ in this population with chronic low back pain (3).

The term facet synovitis or, more accurately zygapophyseal joint synovitis, refers to an acute or subacute inflammation of the zygapophyseal joint without degeneration and typically occurs in younger, active individuals with posterior el-

From *Hospital For Special Surgery, New York, New York, \#Weil Medical School of Cornell University, New York, New York, ${ }^{\star}$ State University of New York at Buffalo, Buffalo, New York, \#\#Columbia University, New York, New York, and ${ }^{\star \star *}$ Triangle Orthopaedic Associates, PA, Durham, North Carolina. Address Correspondence: Vijay B. Vad, MD, Hospital for Special Surgery, 535 East 7oth Street; New York, NY 10021. Email: vadv@hss.edu

Funding: There was no external funding in preparation of this manuscript. intra-articular zygapophyseal joint injection utilizing steroid and local anesthetic agent. Failure to progress led to these athletes receiving percutaneous, fluoroscopically-guided, radiofrequency denervation of the bilateral $L 4-L 5$ and $L 5$-S 1 zygapophyseal joints. A good response to a diagnostic medial branch block was a prerequisite for RFD treatment. In all cases, the medial branch above and below the involved level was treated. Post procedure, all athletes participated in a phased physical therapy program followed by a progressive return to pitching. Success was defined as the ability to return to pre-procedure level of baseball pitching combined with greater than 50\% low back pain reduction. Pre- and post-RFD, Visual Analog (Numeric) Scale (VAS) and Roland-Morris (R-M) tests

ement overuse syndrome (4-9). This is particularly common in athletes placing high demands on the lumbar zygapophyseal joint, such as professional baseball pitchers who incur high torsional torque forces on their lumbar zygapophyseal joint (10-12). These athletes may present with symptoms identical to zygapophyseal joint osteoarthritis but without the radiographic findings typical of spondylosis. In these patients, non-contrast lumbar T2-weighted magnetic resonance imaging (MRI) can demonstrate high signal intensity changes in the zygapophyseal joint space in the absence of any other pathology.

Once the diagnosis of lumbar zygapophyseal joint mediated pain is established, a variety of treatment options may be utilized. Conservative treatment of the lumbar zygapophyseal joint mediated pain traditionally has included a trial of oral anti-inflammatory medications, physical therapy, osteopathic manipulations of the lumbar spine, and intra-articular steroid injection, either alone or in combination (13-20). Medial branch block of the dorsal rami innervating the zygapophyseal joint has been shown to were administered.

Ten out of $12(83 \%)$ athletes were able to return to pitching at a level attained prior to RFD. All 12 patients, experienced statistically significant low back pain relief, with a mean pre-RFD VAS of 8.4; mean post-RFD VAS of 1.7; mean pre-RFD R-M score of 12.3; and mean post-RFD R-M score of 22.3.

In conclusion, athletes, experiencing lumbar zygapophyseal joint mediated low back pain secondary to zygapophyseal joint synovitis and have failed more conservative management may benefit from radiofrequency zygapophyseal joint denervation followed by a formal rehabilitation program.

Keywords: Lumbar zygapophyseal joint, facet joint, synovitis, facet injection, radiofrequency denervation, rehabilitation

be beneficial but may offer only temporary relief (21-23). Anesthetic infiltration of the medial branch can also be used as a diagnostic tool, and if successful in relieving pain, a more definitive multilevel medial branch radiofrequency denervation (RFD) can be attempted (24-27).

In this prospective study, the authors report on their clinical experience utilizing radiofrequency denervation in athletes with lumbar zygapophyseal joint mediated low back pain secondary to lumbar zygapophyseal joint synovitis.

\section{Methods}

This prospective study was conducted at a major teaching hospital after approval from the hospital institutional review board (IRB). All patients were from the private practice of the senior author. The authors treated 12 baseball pitchers who presented with the primary complaint of low back pain (LBP). Physical examination revealed localized, axial, bilateral low back pain exacerbated by lumbar extension and rotation but relieved by sitting. All athletes demonstrated negative tension signs and had no neurological deficits. Other causes for their symptoms 


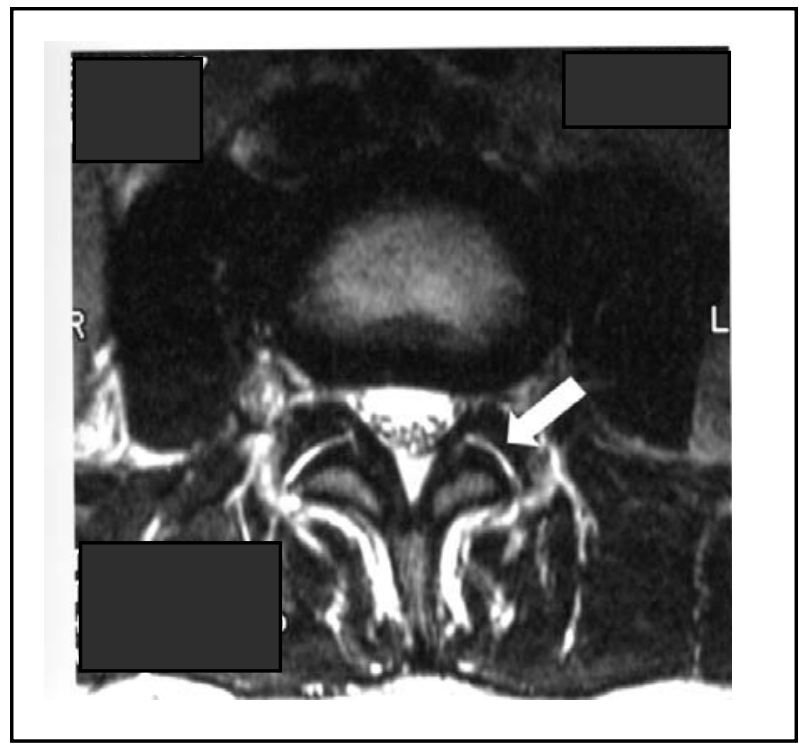

Fig.1 Increased signal intensity changes (solid arrow) of the L 4-5 zygapophyseal joint on magnetic resonance imaging, T2-weighted image.

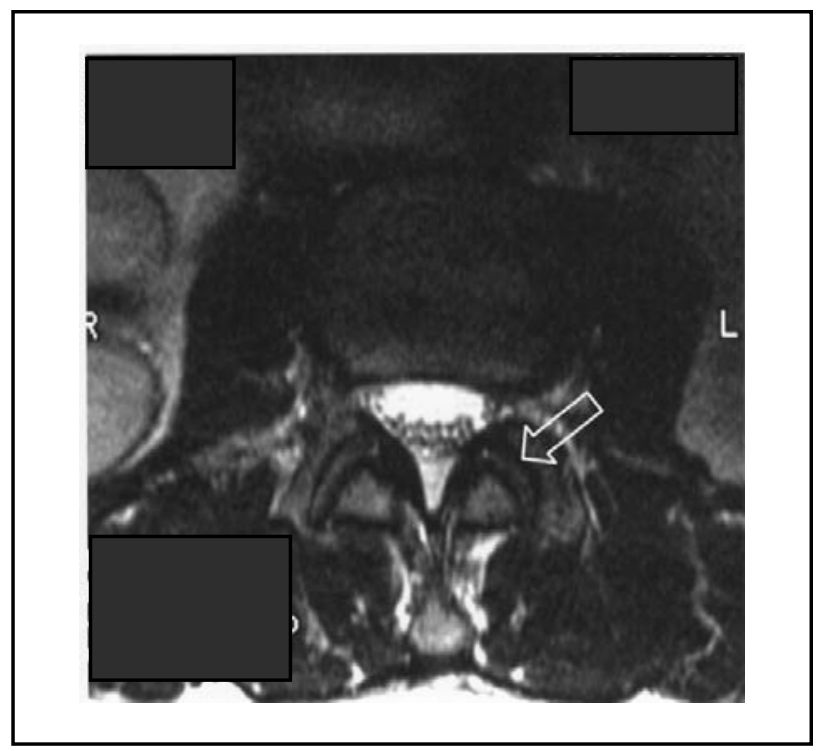

Fig.2 Normal signal intensity (empty arrow) of uninvolved (normal) zygapophyseal joint on magnetic resonance imaging, T2-weighted image.. were excluded, including paraspinal musculature or ligamentous sprain, disc protrusion or herniation, rheumatoid arthritis, degenerative disc disease, spinal stenosis, and spinal fracture. A non-contrast MRI was performed which demonstrated increased signal intensity changes of the L4-L5 zygapophyseal joints bilaterally on T2-weighted images (Fig. 1) when compared to other non-involved levels (Fig. 2).

All patients underwent conservative therapy, including non-steroidal oral anti-inflammatory medications, physical therapy, osteopathic manipulations, and bilateral intra-articular L4-L5 zygapophyseal steroid injection under fluoroscopy. Intra-articular injections were performed using $1 \mathrm{cc}$ Kenalog and $1 \mathrm{cc}$ of $2 \%$ lidocaine. Persistence of symptoms, including difficulty in pitching, at 8-weeks following this initial treatment led to all 12 athletes undergoing a diagnostic nerve block of the L3, L4, and L5 posterior primary rami bilaterally. The medial branch above and below the involved level (L4-L5) was anesthetized to account for the innervation of the zygapophyseal joint from at least two spinal levels $(21,28-33)$. The technique for lumbar medial branch block has been described elsewhere $(21,29,34,35)$. Briefly, with the patient in a prone position on a fluoroscopy table, the skin over the lumbar region was prepared in a sterile fashion. For each target nerve, a 22-gauge 90 mm spinal needle was advanced anteriorly, medially and caudally. The target location for the L3 and L4 medial branch block was the osseous groove at the junction of the superior articular process and the transverse process of the corresponding vertebra. For the L5 dorsal ramus block, the junction of the superior articular process and the ala of the sacrum was the target. It is correctly called a dorsal ramus block because the target injection site is proximal to the medial branch of the dorsal ramus. After confirming, under fluoroscopic guidance, that the tip of the needle in the proper location, the bevel opening was rotated medially and $0.5 \mathrm{ml}$ of radiopaque contrast material (Iohexol (Omnipaque $\left.^{\circledR}\right)$, Nycomed, Roskilde, Denmark) was injected. Contrast flow along the path of the target nerve confirmed adequate placement in all cases and was followed by injection of $0.5 \mathrm{ml}$ of $2 \%$ Xylocaine. This was repeated to obtain accurate medial branch anesthesia at L3-4, L45 and L5-S1 bilaterally. All patients completed a VAS pain rating before and after this diagnostic injection. An independent observer, who determined the response to injection based on the pre- and post-injection VAS score, then evaluated patients. All patients experienced at least $80 \%$ reduction of their low back pain lasting for three hours following this diagnostic medial branch injection and were considered as good candidates for RFD of the L4-5 and L5-S1 zygapophyseal joints.

The technique for lumbar radiofrequency medial branch neurotomy has been described elsewhere (26, 27, 36). Briefly, with the same positioning and preparation as described above, three 22 gauge $90 \mathrm{~mm}$ spinal needles were advanced under fluoroscopic guidance into the osseous grooves

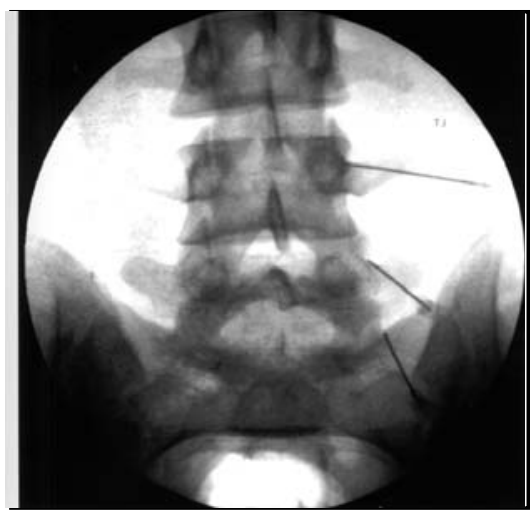

Fig.3 Fluoroscopic view of final positioning of needles residing parallel to the target L3 and L4 medial branch nerves in their osseous grooves, between the superior articular process and the transverse processes of L4 and L5, just proximal to the mamilloaccessory ligament; and in the L5 medial branch nerve osseous grove, just superior to the inferior aspect of the L5-S1 zygapophyseal joint. 
where the L3 and L4 medial branch and the L5 dorsal ramus reside. The tip of the needle was positioned to access the nerve proximally, at the superior edge of the transverse process for the L3 and L4 medial branch or the superior edge of the sacral ala for the L5 dorsal ramus. Confirmation of the needle tip resting on bone in the groove, pointing to the location of the nerve was obtained through oblique, lateral and antero-posterior (AP) views (Figure 3). Three radiofrequency (RF) electrodes (22 gauge, Ray electrode, Radionics, Burlington, MA) were then introduced through the guiding needles under fluoroscopic guidance. The electrode was advanced until its tip was in contact with the target nerve. Lateral views were used to ensure that the tip of the electrode had not ventured beyond the transverse process toward the intervertebral foramen. Oblique views were used to check that the needle was oriented parallel to the course of the target nerve. Once assured of proper radiofrequency needle tip placement, a radiofrequency generator (Model 3FG-3C, Radionics, Burlington, MA) was used to stimulate the target nerve and further confirm placement through corresponding multifidus muscle twitch. Then $0.75 \mathrm{ml}$ of $1 \%$ Xylocaine was injected through the guide needle to anesthetize the target nerve. After injection, the guide needle was withdrawn approximately $2 \mathrm{~cm}$ to avoid radiofrequency dispersal through its shaft and final fluoroscopic confirmation of RF needle tip placement was performed. A RF lesion was then made by raising the temperature of the tip of the electrode to $85^{\circ} \mathrm{C}$ for 90 seconds. A second lesion was made after carefully withdrawing the RF needle 5 $\mathrm{mm}$. In this manner, the target nerve was coagulated $10 \mathrm{~mm}$ along its length distal to the mamilloaccessory ligament. The described procedure was performed bilaterally.

All patients received oral hydrocodone for post-procedure pain relief for a total of one week. Formal rehabilitation program was started once adequate pain control had been achieved. A phased program of physical therapy was established for all athletes, with aquatherapy, stretching and active range of motion exercises as the initial intervention, followed by isometric strengthening exercises of the back extensor musculature (37). The rehabilitation program culminated with a slowly progressive return to pitching at 8 to 12 weeks post-procedure.

\section{RESULTS}

There were twelve male pitchers with an average age of 22.3 years (range: 19 to 26 years). Successful primary outcome was defined as the ability to return to pitching, with a reduction in functional disability and pain of at least $50 \%$ as measured by standardized scoring techniques as secondary outcomes. To this effect, the Visual Analog (Numerical) Scale (VAS) for pain $(38,39)$ and Roland-Morris (RM) (40) functional outcome measures were collected pre-treatment, and at onemonth, three-month, and one year posttreatment. Mean VAS before treatment was $8.4(\mathrm{SD}=1.4)$; mean VAS after treatment was 1.7 ( $\mathrm{SD}=1.3)$; mean R-M pretreatment was $12.3(\mathrm{SD}=1.8)$; and mean $\mathrm{R}-\mathrm{M}$ post-treatment was $22.3(\mathrm{SD}=1.4)$. The Wilcox signed rank test was used for statistical analysis of the data pre- and post-treatment (matched pairs). With a 95\% confidence interval, there was a statistically significant improvement in pain for all 12 patients $(\mathrm{p}<0.05)$ after treatment. Ten out of $12(83 \%)$ RFD-treated athletes have been able to return to pitching at the level attained prior to this therapeutic intervention. To date, the median follow-up after treatment was 1.3 years (range: 1 to 2.1 years). Follow-up continues to the present day, and has reached 2.1 years for the first athlete treated.

\section{Discussion}

The lumbar zygapophyseal or facet joint has been considered a potential source of low back pain since the early 1900's (41,42). These are bilateral synovial articulations of the spine linking two adjacent vertebrae posteriorly. Hyaline cartilage lines the articulating surface of the zygapophyseal joint and synovial fluid fills the space between them. This construct is enclosed in a fibrous capsule, which receives innervation from at least two medial branches arising from the dorsal rami of spinal nerves above and below $(32,33,43-53)$. The lumbar facet joint is considered a significant source of low back pain in the general population (54-57). Specifically, spondylosis of the lumbar zygapophyseal joint is a well recognized cause of low back pain with typical clinical findings being axial, non-radiating, paraspinal pain, usually in an older individual, exacerbated by lumbar extension and relieved by sitting (58-59). Radiographic abnormalities and arthrogra- phy findings of the zygapophyseal joint include narrowing of the facet joint space and degeneration of the articular surfaces (60-64).

The lumbar zygapophyseal joint is a true synovial joint with rich innervation, containing free, encapsulated and nonencapsulated nerve endings (65-67). Fibers of these nociceptive nerves as well as substance $P$ and neuropeptide receptors have been identified in the joint capsule $(46,53)$. Biomechanical studies in cadavers have demonstrated that the capsular ligament of the lumbar zygapophyseal joint can suffer mechanical overstress (68). With significant facet loading, the inferior tip of the facets will make contact with the laminae below and act as a pivot point for the whole vertebra causing stretching of the capsule (69). Furthermore, in order to maintain spinal segmental stability against ventral loading, the erector paraspinal musculature will undergo isometric contraction, thus increasing the strain on the facet capsule (70). The convergence of the resulting force vectors on the zygapophyseal joint capsule has been shown to cause tissue injury, micro-hemorrhage and inflammation with subsequent prolonged nociceptor excitation (71).

Baseball pitchers require a rigid cylinder of strength in order to transfer torque from their legs to their throwing arm (10,72). Developing power for the throw involves a rotational motion of this cylinder, which starts at the legs and is then transferred to the hips and the lumbar spine (10). Due to their orientation, the lumbar facet joints oppose rotational inputs on the lumbar spine and will act as a solid construct when rotational force is applied $(73,74)$. This mechanical effect is compounded by the isometric contraction of paraspinal extensor musculature and results in the transfer of the full torque force cephalad, towards the thoracic spine, the shoulder and finally the arm. Throwing a baseball at high speed is a violent motion, which places extreme torsion and extension strains on the lumbar zygapophyseal joint $(11,75)$. In our study, the mechanism of injury presumably involved recurring lumbar facet joint capsule stretch, synovial membrane injury, and inflammation secondary to the cumulative effects of the numerous pitching actions executed by the players during their careers. The repetitive trauma resulted in low back pain and inability to 
pitch at a level. These athletes had failed oral medications, physical therapy, and intra-articular injections but also osteopathic manipulations which can sometimes be helpful in patients who do not plan to undertake high level activities such as pitching (20).

MRI is a sensitive but not specific diagnostic tool for intraarticular zygapophyseal joint pathology and has been shown to be superior to computed tomography or SPECT scan for this purpose $(63,76-$ 80). Specifically, facet joint synovitis has been shown to result in hyperintense signal changes of the intraarticular space which can be detected as early as one week after injury and probably represent proteinaceous exudate and deoxy-hemoglobin breakdown products (81-82). These MRI findings in an athlete with acute onset of low back pain are suggestive but not diagnostic of lumbar facet joint synovitis. The differential diagnosis may include septic arthritis (78,83-85), synovial chondromatosis (86) or even small synovial cysts in which there is enlargement of the joint space in a true cystic manner (87-88). A thorough medical workup to exclude other sources of facet joint pathology should be performed prior to initiation of treatment, including sedimentation rate, C-reactive protein, and peripheral white cell count $(87,89)$.

In our study, once the presumptive diagnosis of zygapophyseal joint synovitis had been made, all athletes underwent a conservative treatment trial consisting of oral non-steroidal anti-inflammatory medication, physical therapy, intra-articular injections, and osteopathic manipulations (19-20,37). If low back pain persisted after conservative treatment, diagnostic zygapophyseal joint blocks were performed. The lumbar zygapophyseal joint can be anesthetized by direct intraarticular injection of local anesthetic or by infiltration of the medial branches of the dorsal rami. To block the nerve supply to a lumbar zygapophyseal joint, at least two medial branches should be anesthetized because of its dual innervation from the branch at and above the suspected painful joint. Failure to do this can result in up to
$40 \%$ of non-diagnostic blocks (90). Additional innervation of the zygapophyseal joint from the next more caudal medial branch has also been reported $(31,91)$. To achieve complete lumbar zygapophyseal joint anesthesia, the authors advocate, in addition to the medial branch at the involved level, anesthetizing the branch above and below the suspected level. This minimizes the incidence of non-diagnostic blocks and adds minimally to the length of the procedure.

Careful patient selection through a positive response to medial branch block has been shown to be the only predictor of a good outcome for zygapophyseal joint denervation (26). In our study, those athletes who had failed more conservative therapy but had a satisfactory response to medial branch block underwent radiofrequency denervation of the facet joints. Both L4-L and L5-S1 facets were denervated bilaterally in order to insure adequate denervation. Parallel needle placement techniques under direct fluoroscopic imaging performed by an experienced physician have been shown to result in over $90 \%$ denervation rate (26). Preliminary stimulation of the target nerve to confirm needle placement prior to neurotomy can be performed. Electromyographic (EMG) testing of the multifidus muscle innervated by the target medial branches after radiofrequency denervation has also been utilized to confirm the accuracy and thoroughness of the procedure (26). This could be especially useful when pain still persists after the procedure and all examined multifidi levels where neurotomy was attempted lack EMG signs of denervation. If needle EMG is going to be utilized for denervation documentation, baseline testing should be accomplished prior to RFD, since many systemic and local conditions can cause a similar denervation pattern unrelated to the procedure. In our study, needle EMG confirmation of the efficacy of RFD or baseline needle EMG testing was not performed. It is our experience that a good response to multilevel, bilateral medial branch anesthesia is a sufficiently accurate predictor of pain relief after RFD as long as a re- fined operative technique is applied. The essential requirement is the precise placement of the electrode in the target osseous groove under direct fluoroscopic guidance by a skilled operator. If this can be accomplished successfully, the use of preliminary stimulation or post-procedure EMG is superfluous. In addition, while evidence of this denervation on EMG indicates that the RFD successfully coagulated this nerve, the results do not correlate with symptom improvement (26).

No long-term complications have been documented after medial branch RFD. Arthritic changes of the treated joint has been suggested but never demonstrated. Although medial branch RFD denervates the zygapophyseal joint, the segment is not rendered unstable, since the disc, osseous and ligamentous structures and most of the paraspinal musculature at that level remain unchanged (36). Furthermore, there are no reports of increased frequency of lumbar injury in patients treated with RFD of the lumbar zygapophyseal joints despite a growing number of such patients and many years of accumulated follow-up. Rarely, patients will notice discomfort and short-term cutaneous pain or hypersensitivity in the postoperative period. When it occurs it is transient and usually subsides in 4-to-6 weeks.

\section{Conclusion}

In this study, 12 baseball pitchers who had failed more conservative treatment for disabling lumbar zygapophyseal joint synovitis underwent RFD of the affected zygapophyseal joints. Medial branch RFD followed by a postoperative rehabilitation regime offered significant relief of back pain and the ability to return to pitching. All athletes tolerated the procedure well and no complications have been noted to date. It is the authors' belief that if accurate diagnosis and a meticulous technique is employed, lumbar zygapophyseal joint radiofrequency denervation can be an effective, safe, long-term pain control measure that can facilitate an athlete's recovery of function by enabling a formal rehabilitation program without pain. 


\section{Author Affiliation}

Vijay B. Vad, MD

Attending Physician

Hospital for Special Surgery

Assistant Professor

Weil Medical School of Cornell

University

535 East $70^{\text {th }}$ Street

New York, NY 10021

E-mail:vadv@hss.edu

\section{William G. Cano, MD}

Resident

Department of Physical Medicine and Rehabilitation

State University of New York at Buffalo

515 Kimball Tower

Buffalo, NY 14223

\section{Dilshaad Basrai, BS}

Program in Physical Therapy

Columbia University

710 West 168th, 8th Floor

New York, NY 10032

\section{Gregory E. Lutz, MD}

Chief Physiatrist

Associate Professor

Hospital for Special Surgery

Weil Medical School of Cornell University

535 East 70th Street

New York, NY 10021

\section{Atul Bhat, MD}

Triangle Orthopaedic Associates, P.A., 120 William Penn Plaza

Independence Park

Durham, North Carolina 27704

\section{References}

1. Cypress BK. Characteristics of physician visits for back symptoms: A national perspective. Am J Public Health 1983; 73:389395.

2. Bogduk N. The innervation of the lumbar spine. Spine 1983; 8:286-293.

3. Manchikanti L, Singh V, Pampati V et al. Evaluation of the relative contributions of various structures in chronic low back pain. Pain Physician 2001; 4:308-316.

4. Micheli LJ, Wood R. Back pain in young athletes. Significant differences from adults in causes and patterns. Arch Pediatr Adolesc Med 1995; 149:15-18.

5. d'Hemecourt PA, Gerbino PG $2^{\text {nd }}$, Micheli LJ. Back injuries in the young athlete. Clin Sports Med 2000; 19:663-679.

6. Harvey J, Tanner S. Low back pain in young athletes. A practical approach. Sports Med 1991; 12:394-406.

7. Solomon R, Brown T, Gerbino PG, et al. The young dancer. Clin Sports Med 2000; 19: 717-739.

8. Zetaruk MN. The young gymnast. Clin Sports Med 2000; 19:757-780.

9. Helbig T, Lee CK. The lumbar facet syndrome. Spine 1988; 13:61-64.

10. Watkins RG, Dennis S, Dillin WH et al. Dynamic EMG analysis of torque transfer in professional baseball pitchers. Spine 1989; 14:404-408.

11. Watkins RG, Dillin WH. Lumbar spine injury in the athlete. Clin Sports Med 1990; 9: 419-448.

12. McFarland EG, Wasik M. Epidemiology of collegiate baseball injuries. Clin / Sport Med 1998; 8:10-13.

13. Carette S, Marcoux S, Truchon R et al. A controlled trial of corticosteroid injections into facet joints for chronic low back pain. N Engl J Med 1991; 325:1002-1007.

14. Carrera GF. Lumbar facet joint injection in low back pain and sciatica: preliminary results. Radiology 1980; 137:665-667.

15. Lau LS, Littlejohn GO, Miller MH. Clinical evaluation of intra-articular injections for lumbar facet joint pain. Med J Aust 1985: 143:563-565.

16. Jackson RP, Jacobs RR, Montesano PX. 1988 Volvo award in clinical sciences. Facet joint injection in low-back pain. A prospective statistical study. Spine 1988; 13: 966-971.

17. Lippitt $A B$. The facet joint and its role in spine pain. Management with facet joint injections. Spine 1984; 9:746-750.

18. Lynch MC, Taylor JF. Facet joint injection for low back pain. A clinical study. J Bone Joint Surg Br 1986; 68:138-141.

19. Shekelle PG. Spinal manipulation. Spine 1994; 19:858-861.

20. Andersson GB, Lucente T, Davis AM et al. A comparison of osteopathic spinal manipulation with standard care for patients with low back pain. N Engl J Med 1999; 341:1426-1431.

21. Bogduk N. International Spinal Injection Society guidelines for the performance of spinal injection procedures. Part 1: Zygapophysial joint blocks. Clin J Pain 1997; 13:285-302.

22. Bogduk N, Aprill C, Derby R. Lumbar zygapophyseal joint pain: diagnostic blocks and therapy. In Wilson DJ (ed). Interventional Radiology of the Musculoskeletal System. Edward Arnold, London, 1995, pp3-86.

23. Dreyfuss $P$, Schwarzer AC, Lau $P$ et al. Specificity of lumbar medial branch and $L_{5}$ dorsal ramus blocks. A computed tomog. raphy study. Spine 1997; 22:895-902.

24. Boas RA. Nerve blocks in the diagnosis of low back pain. Neurosurg Clin N Am 1991; 2:807-816.

25. Bogduk N, Aprill C, Derby R. Diagnostic blocks of spinal synovial joints. In White AH (ed). Spine Care, Diagnosis and Conservative Treatment, Vol 1. Mosby, St. Louis, 1995, pp 298-321.
26. Dreyfuss P, Halbrook B, Pauza K et al. Efficacy and validity of radiofrequency neurotomy for chronic lumbar zygapophysial joint pain. Spine 2000; 25:1270-1277.

27. van Kleef $M$, Barendse GA, Kessels A et al. Randomized trial of radiofrequency lumbar facet denervation for chronic low back pain. Spine 1999; 24:1937-1942.

28. Bogduk N, Wilson AS, Tynan W. The human lumbar dorsal rami. J Anat 1982; 134(Pt 2):383-397.

29. Bogduk N. Back pain: Zygapophyseal joint blocks and epidural steroids. In Cousins MJ, Brindenbaugh PO (eds). Neural Blockade in Clinical Anesthesia and Pain Management, 2nd ed. J.B. Lippincott, Philadelphia, 1990, pp 935-954.

30. Bogduk N, Macintosh J, Marsland A. Technical limitations to the efficacy of radiofrequency neurotomy for spinal pain. Neurosurgery 1987; 20:529-535.

31. Taguchi T, Kawai S, Oda H et al. Anatomic basis for selective nervi-spinales infiltration in the treatment of articular back pain. J Neuroradiol 2000; 27:25-29.

32. Dreyer SJ, Dreyfuss P, Cole AJ. Posterior elements (facet and sacroiliac joints) and low back pain. Phys Med Rehabil Rev 1999; 13:443-471.

33. Suseki K, Takahashi Y, Takahashi K et al. Innervation of the lumbar facet joints. Origins and functions. Spine 1997; 22:477485.

34. Destouet JM, Gilula LA, Murphy WA et al. Lumbar facet joint injection: Indication, technique, clinical correlation, and preliminary results. Radiology 1982; 145:321325.

35. Kaplan M, Dreyfuss P, Halbrook B et al. The ability of lumbar medial branch blocks to anesthetize the zygapophysial joint. A physiologic challenge. Spine 1998; 23: 1847-1852.

36. Dreyfuss P, Rogers CJ. Radiofrequency neurotomy of the zygapophyseal and sacroiliac joints. In Lennard (ed). Pain Procedures in Clinical Practice. Hanley and Belfus, Philadelphia, 2000 pp 395-420.

37. Lutz GE, Vad VB, Wisneski RJ. Segmental instability: Rehabilitation considerations. Seminars Spine Surg 1996; 8:332-338.

38. Revill SI, Robinson JO, Rosen $\mathrm{M}$ et al. The reliability of a linear analogue for evaluating pain. Anaesthesia 1976; 31:1191-1198.

39. Jensen MP, Karoly P, Braver S. The measurement of clinical pain intensity: a comparison of six methods. Pain 1986; 27:117126.

40. Roland M, Morris R. A study of the natural history of back pain. Part I: Development of a reliable and sensitive measure of disability in low-back pain. Spine 1983; 8:141-144.

41. Goldthwaith JE. The lumbosacral articulation: an explanation of many cases of lumbago, sciatica and paraplegia. Boston Med Surg / 1911; 164: 365-372.

42. Ghormley RK. Low back pain with special 
reference to the articular facets and presentation of a surgical procedure. JAMA 1933; 101:1773-1777.

43. Lewin T, Moffet B, Viidick A. The morphology of the lumbar synovial intervertebral joints. Acta Morphol Neerlando-Scandinav 1962; 4:299-319.

44. Bogduk N, Twomey LT. Clinical anatomy of the lumbar spine, 2nd ed. Churchill Livingstone, London, 1991.

45. Bogduk N, Engel R. The menisci of the lumbar zygapophyseal joints. A review of their anatomy and clinical significance. Spine 1984; 9:454-460.

46. Ashton IK, Ashton BA, Gibson SJ et al. Morphological basis for back pain: the demonstration of nerve fibers and neuropeptides in the lumbar facet joint capsule but not in ligamentum flavum. J Orthop Res 1992; 10:72-78.

47. Avramov Al, Cavanaugh JM, Ozaktay CA et al. The effects of controlled mechanical loading on group-II, III, and IV afferent units from the lumbar facet joint and surrounding tissue. An in vitro study. J Bone Joint Surg Am 1992; 74:1464-1471.

48. Cavanaugh JM, Ozaktay AC, Yamashita T et al. Mechanisms of low back pain: a neurophysiologic and neuroanatomic study. Clin Orthop 1997; 335:166-180.

49. Cyron BM, Hutton WC. The tensile strength of the capsular ligaments of the apophyseal joints. J Anat 1981; 132 (Pt 1):145-150.

50. McLain RF, Pickar JG. Mechanoreceptor endings in human thoracic and lumbar facet joints. Spine 1998; 23:168-173.

51. Yahia LH, Garzon S. Structure on the capsular ligaments of the facet joints. Ann Anat 1993; 175:185-188.

52. Giles LG, Taylor JR. Human zygapophyseal joint capsule and synovial fold innervation. Br J Rheumatol 1987; 26:93-98.

53. Giles LG, Harvey AR. Immunohistochemical demonstration of nociceptors in the capsule and synovial folds of human zyg apophyseal joints. Br J Rheumatol 1987; 26:362-364.

54. Schwarzer AC, Aprill CN, Derby R et al. The relative contributions of the disc and zyg apophyseal joint in chronic low back pain. Spine 1994; 19:801-806.

55. Dreyer SJ, Dreyfuss PH. Low back pain and the zygapophysial (facet) joints. Arch Phys Med Rehabil 1996; 77:290-300.

56. Nachemson AL. Advances in low-back pain. Clin Orthop 1985;(200):266-78.

57. Schwarzer AC, Wang SC, Bogduk N et al. Prevalence and clinical features of lumbar zygapophysial joint pain: A study in an Australian population with chronic low back pain. Ann Rheum Dis 1995; 54:100106.

58. Lewinnek GE, Warfield CA. Facet joint degeneration as a cause of low back pain. Clin Orthop 1986; 213:216-222.

59. Fujiwara A, Lim TH, An HS et al. The effect of disc degeneration and facet joint osteo- arthritis on the segmental flexibility of the lumbar spine. Spine 2000; 25:3036-3044.

6o. Lawrence JS, Bremner JM, Bier F. Osteo-arthrosis. Prevalence in the population and relationship between symptoms and $x$-ray changes. Ann Rheum Dis 1966; 25:1-24.

61. Carrera GF, Williams AL. Current concepts in evaluation of the lumbar facet joints. Crit Rev Diagn Imaging 1984; 21:85-104.

62. Park WM, McCall IW, Benson D et al. Spondylarthrography: The demonstration of spondylolysis by apophyseal joint arthrography. Clin Radiol 1985; 36:427-430.

63. Fujiwara A, Tamai K, Yamato $M$ et al. The relationship between facet joint osteoarthritis and disc degeneration of the lumbar spine: an MRI study. Eur Spine J 1999; 8:396-401.

64. Magora A, Schwartz A. Relation between the low back pain syndrome and $x$-ray findings. 2. Transitional vertebra (mainly sacralization). Scand J Rehabil Med 1978; 10:135-145.

65. Hirsch D, Ingelmark B, Miller M. The anatomical basis for low back pain. Acta Orthop Scand 1963; 33:1-17.

66. Jackson $\mathrm{HC} 2^{\text {nd }}$, Winkelmann RK, Bickel WH. Nerve endings in the human lumbar spinal column and related structures. J Bone Joint Surg Am 1966; 48:1272-1281.

67. Yamashita T, Cavanaugh JM, el-Bohy AA et al. Mechanosensitive afferent units in the lumbar facet joint. J Bone Joint Surg Am 1990; 72:865-870.

68. El-Bohy AA, Goldberg SJ, King Al. Measurement of facet capsular stretch. In Proceedings of the conference of the American Society of Mechanical Engineers. AMD, New York, 1987; 84:161-164.

69. Yang KH, King Al. Mechanism of facet load transmission as a hypothesis for low-back pain. Spine 1984; 9:557-565.

70. El-Bohy AA, Yang KH, King Al. Experimental verification of facet load transmission by direct measurement of facet lamina contact pressure. J Biomech 1989; 22:931941.

71. Cavanaugh JM, Ozaktay AC, Yamashita HT et al. Lumbar facet pain: Biomechanics, neuroanatomy and neurophysiology. J Biomech 1996; 29:1117-1129.

72. Young JL, Casazza BA, Press JM et al. Biomechanical aspects of the spine in pitch ing. In Andrews JR, Zarins B, Wilk KE (eds). Injuries in baseball. Lippincott-Raven, Philadelphia, 1998:30-43.

73. van Schaik JP, van Pinxteren B, Verbiest $H$ et al. The facet orientation circle. A new parameter for facet joint angulation in the lower lumbar spine. Spine 1997; 22:531536.

74. Tulsi RS, Hermanis GM. A study of the angle of inclination and facet curvature of superior lumbar zygapophyseal facets. Spine 1993; 18:1311-1317.

75. Farfan HF. The torsional injury of the lumbar spine. Spine 1984; 9:53.
76. Morrison JL, Kaplan PA, Dussault RG et al. Pedicle marrow signal intensity changes in the lumbar spine: a manifestation of facetdegenerative joint disease. Skeletal $\mathrm{Ra}$ diolo 2000; 29:703-707.

77. Okazaki K, Sasaki K, Matsuda S et al. Pyogenic arthritis of a lumbar facet joint. $A m$ J Orthop 2000; 29:222-224.

78. Fujiwara A, Tamai K, Yamato M et al. Septic arthritis of a lumbar facet joint: Report of a case with early MRI findings. I Spinal Disord 1998; 11:452-453.

79. Farrokh D. Isolated septic arthritis of the articular surface of the lumbar spine--the

contribution of MRI (French). J Belge Radiol 1997; 80:289-291.

8o. Douvrin F, Callonnec F, Proust F et al. Lumbar interapophyseal septic arthritis. Apropos of 3 cases (French). J Neuroradiol 1996; 23:234-240.

81. Palmer JL, Bertone AL, Malemud CJ et al. Biochemical and biomechanical alterations in equine articular cartilage following an experimentally-induced synovitis. Osteoarthritis Cartilage 1996; 4:127-137.

82. Østergaard $M$, Stoltenberg M, Henriksen 0 et al. The accuracy of MRI-determined synovial membrane and joint effusion volumes in arthritis. A comparison of pre- and post-aspiration volumes. Scand ) Rheumatol 1995; 24:305-311.

83. Dayer MJ, Gransden W, Goldsmith DJ. Facet joint osteomyelitis in a patient on longterm hemodialysis. Am J Kidney Dis 2000; 36:1041-1044.

84. Pilleul F, Garcia J. Septic arthritis of the spine facet joint: early positive diagnosis on magnetic resonance imaging. Review of two cases. Joint Bone Spine 2000; 67: 234-237.

85. Rombauts PA, Linden PM, Buyse AJ et al. Septic arthritis of a lumbar facet joint caused by Staphylococcus aureus. Spine 2000; 25:1736-1738.

86. Burrafato V, Campanacci DA, Franchi $A$ et al. Synovial chondromatosis in a lumbar apophyseal joint. Skeletal Radiol 1998; 27:385-387

87. Kjerulf TD, Terry DW Jr., Boubelik RJ. Lumbar synovial or ganglion cysts. Neurosurgery 1986; 19:415-420.

88. Apostolaki E, Davies AM, Evans $\mathrm{N}$ et al. MR imaging of lumbar facet joint synovial cysts. Eur Radiol 2000;10:615-623.

89. Ergan $M$, Macro $M$, Benhamou $C L$ et al. Septic arthritis of lumbar facet joints. A review of six cases. Rev Rhum Engl Ed 1997; 64:386-395.

90. Schwarzer AC, Aprill CN, Derby R et al. The false-positive rate of uncontrolled diagnostic blocks of the lumbar zygapophysial joints. Pain 1994; 58:195-200.

91. Paris SV. Anatomy as related to function and pain. Orthop Clin North Am 1983; 14: 475-489. 